\title{
Prevalence of Salmonella in broilers at retail outlets, processing plants and farms in Malaysia
}

\begin{abstract}
A study was conducted to estimate the prevalence of Salmonella among broilers retailed at wet-markets and processing plants. Litter and feed samples obtained from both broiler and breeder farms were also examined for Salmonella. A total of 158 out of 445 (35.5\%) and 52 out of $104(50.0 \%)$ broiler carcasses obtained from wet-markets and processing plants were contaminated with Salmonella, respectively. Salmonella was isolated from 14 out of 98 (14.3\%) samples of intestinal content. Litter samples from broiler and breeder farms were positive for Salmonella, 8/40 (20\%) and 2/10 (20\%), respectively. Salmonella isolates (230) belonging to 15 different serovars were isolated. Predominant serovars were S. enteritidis, S. muenchen, S. kentucky and S. blockley.
\end{abstract}

Keyword: Salmonella; Prevalence; Poultry; Retail outlets; Processing plants 